\title{
Network governance and regional resilience to climate change: empirical evidence from mountain tourism communities in the Swiss Gotthard region
}

\author{
Tobias Luthe $\cdot$ Romano Wyss $\cdot$ Markus Schuckert
}

Received: 18 November 2011 / Accepted: 22 February 2012/Published online: 15 March 2012

(C) Springer-Verlag 2012

\begin{abstract}
Mountain regions and peripheral communities, which often depend on few economic sectors, are among the most exposed and sensitive to climate change. Governance of such socio-economic-ecological networks plays a strong role in determining their resilience. Social processes of governance, such as collaboration between communities, can be systematically assessed through the existence and strength of connections between actors and their embeddedness in the broader socio-economic network by social network analysis (SNA). This paper examines how network governance of the tourism industry-dependent Swiss Gotthard region relates to resilience to climate change by SNA. The paper argues that economic diversification and a network structure supporting stability, flexibility, and innovation increase regional resilience to climate change. The Gotthard network has a high diversification capability due to high cohesion and close collaboration, limited innovative capacity by the existence of only two subgroups, and considerable flexibility through the centralized structure. Main weaknesses are a low density, uneven distribution of power, and a lack of integration of some supply chain sectors into the overall network.
\end{abstract}

Electronic supplementary material The online version of this article (doi:10.1007/s10113-012-0294-5) contains supplementary material, which is available to authorized users.

T. Luthe $(\bowtie) \cdot R$. Wyss

Institute for Tourism and Leisure Research,

University of Applied Sciences HTW Chur,

Comercialstrasse 22, 7000 Chur, Switzerland

e-mail: tobias.luthe@htwchur.ch

M. Schuckert

School of Hotel and Tourism Management,

The Hong Kong Polytechnic University, Suite 711,

17 Science Museum Road, TST East, Kowloon, Hong Kong
Keywords Social network analysis · Vulnerability · Adaptive capacity · Mountain communities .

Regional environmental change

\section{A resilience framework for vulnerable communities}

The resilience of an ecological system is defined by three characteristics: (1) the capacity of the system to withstand a disturbance while maintaining its basic functions, (2) the ability to self-organize, and (3) the ability to increase its capacity to learn and adapt (Janssen 2007; Walker and Salt 2006). A simple reapplication of the ecological resilience concept to socio-ecological systems will lead to normative and conceptual difficulties (Adger 2000; Duit and Galaz 2008). Existing ecological resilience models, such as the adaptive cycles model (Gunderson and Holling 2002), have been discussed mostly in the context of unexpected, adverse conditions such as large-scale disturbances or accumulated minor disruptions (Vogus and Sutcliffe 2007). Linnenluecke and Griffiths (2010) discuss resilience from an organizational angle and extend the model of adaptive cycles to a business context (Linnenluecke and Griffiths 2010), though there have been other scholars exploring organizational resilience (Vogus and Sutcliffe 2007; Weick et al. 1999; Weick and Roberts 1993). The main aspects of organizational resilience are "the continuing capacity to recover from disturbances as well as the capacity to rebound from adversity in a strengthened and more resourceful way" (Linnenluecke et al. 2012). Current models and frameworks of organizational resilience are not sufficiently equipped for practical and research purpose (Vogus and Sutcliffe 2007) and not suitable to understand resilience in light of significant shifts in climate and weather patterns. Gradual changes like climate change can 
as well exceed thresholds and prompt abrupt and severe changes (Linnenluecke et al. 2012; Linnenluecke and Griffiths 2010).

Organizations often tend to focus on short-term economic goals as opposed to prepare for longer-term changes such as climate change (Starik and Rands 1995). In addition to further strategic capabilities (like identifying future vulnerabilities in a system's understanding or diversifying production activities, e.g., Wilbanks et al. 2007), organizations need to develop new partnerships, better knowledge integration, and spread risks across networks (Wilbanks et al. 2007). The legal framework has to allow for such developments as well, and governments have to provide third-party support to vulnerable organizations and economic sectors.

Up to a certain degree of impact emanating from an outside force, the system can cope with the stress by enforcing the activity pattern that has shown to be successful in the past by investing in the given infrastructure, and putting more financial or labor-resources into certain activities (Folke 2006) — in our case of tourism in alpine areas investments in snow-making capacities to maintain skiing activities, or increased marketing efforts.

When a certain threshold hast past, the mere insisting on given patterns of actions and routines becomes to be obsolete (e.g., since customers no longer demand the product or the product can longer be produced due to substantial disruptions from the outside), and the whole system - as well as the individual actors that make up the system-must adapt by shifting to another production regime (Hassink 2010; Ruiz-Ballesteros 2011).

Network governance in the context of resilience

In vulnerable communities, spreading the risks and the exposure on a diversified economic system is one strategy of community adaptation (Kelman and Lewis 2005; Kelly and Adger 2000). It requires the sectoral and cross-sectoral participation of stakeholders, despite internal or external barriers, in order to maintain and further develop the whole supply chain of the economic system at stake, as well as to govern the broader socio-ecological system successfully. Network governance in this context is understood as "the structures and processes by which collective action among a diversity of social actors is coordinated toward upholding certain publicly held values and resources" (Ernstson et al. 2010; Lebel et al. 2006; Stoker 1998).

A network perspective on organizations might provide more insights into understanding resilience-and more specifically resilient network structures-since organizations are complex networks consisting of various actors and information flows (Webb and Bodin 2008). According to Manring (2007), a functioning network governance structure in the realm of resilience is built to meet two fundamental criteria derived from the literature on adaptive comanagement and adaptive governance (Folke et al. 2005): (1) Preparing for disturbance by creating and maintaining diversity and (2) responding to disturbance by creating and maintaining flexibility. A resilient network governance structure should be able to quickly switch between the two modes defined by these criteria in order "to prepare to change (by enhancing decentralized processes of social learning) and respond to change (by more centralized collective action)" (Ernstson et al. 2010).

Diversification and innovation in a community development context are strongly linked to the structure of the local economy, as well as to the dependency on single industry sectors. It is argued that the diversification of a community's economy, the communities' positions, and their communication flows within the governance network have a strong influence on the overall adaptive capacity (Ingold et al. 2010; Hirschi 2010). In general, social networks take an important role in governing and managing adaptation, since adaptation requires different forms of collaboration, such as learning, information sharing, conflict resolution, or simply coordination (Newig et al. 2010; Bodin and Crona 2009; Manring 2007; Folke et al. 2005). Such collaborations depend on the existence and strength of social connections or ties between actors.

Social relations may not only lead to collaboration, they may also enhance development of knowledge through the exposure to new ideas and the availability of more information (Bodin and Crona 2009). The correlation of network density and collaboration is not continuously increasing though but might decrease from a certain density threshold on. Very high density reduces a network's collective abilities (Oh et al. 2004) and can lead to homogenization of information and knowledge, resulting in reduced adaptive capacities (Little and McDonald 2007; Bodin and Norberg 2005). Highly centralized networks have advantages with collective action in resource governance mainly due to enhancing central actors' abilities to coordinate and prioritize (Sandström and Carlsson 2008), but disadvantages through uneven distribution of power and influence (Ernstson et al. 2008), making such networks inappropriate for solving complex problems.

The structure of a governance network and internal influences within a community can be analyzed by looking at the structure of its social network, in a quantitative and a qualitative way. Characterizing how vertical (Davis and Marquis 2005; Granberg and Elander 2007) and horizontal (Kern and Bulkeley 2009; Young and Lipton 2006) integration of decision-making complement each other is particularly relevant to how communities adapt to change, which is fundamentally cross-sectoral in nature. A systematic identification of horizontal and vertical integration 
patterns delivers a governance network in which local societies can be analyzed (Cash et al. 2006).

Quantitative network properties related to resilience

Social networks can be analyzed by their overall density, cohesion, overall centralization, and collaboration measures, by centrality degrees and by the varieties of ties between actors and actor groups. Network density describes the relation of existing ties to the overall possible number of ties. In the network governance literature, the positive relation between density and joint action or adaptive capacity is supported - the denser the network, the higher the chances for collaboration (Olsson et al. 2004). Empirical studies have shown that a denser network increases collaboration between actors, while it is especially important that many relational ties exist between actors of different kinds (Sandström and Carlsson 2008).

The clustering coefficient can be interpreted as the average probability that actors are part of a collaborative group or that such collaborative groups exist (Baggio et al. 2010). A high clustering coefficient increases the speed of information within the network, which is of relevance to prepare and respond to change.

The level of cohesion describes the existence of subgroups and how they relate to each other (Wassermann and Faust 1994). A network with high structural cohesion misses clearly distinguishable subgroups, whereas the existence of subgroups may hinder collaboration within the whole network due to the high portion of strong, bonding ties within such subgroups (Bodin and Crona 2009). The modularity coefficient can describe the existence of modules or subgroups with denser links in between its members than to other actors. If predefined modules exist, such as supply chain sectors and municipalities in a tourism region as in the case of this paper, the modularity coefficient of each subgroup can be compared with the modularity coefficient of the same network that has been randomized before. If differences are found, the network self-organizes in a different way from the defined one, which must then be taken into account when deciding how to govern the system (Baggio 2011). If the predefined modules exist, then their modularity coefficient must be higher than the reference (Costa et al. 2007).

Centrality measures describe the importance of single actors for the network. Degree centrality is based on the sheer number of ties an actor has and a measure for their ability to make their concerns heard and actively steer governance processes. Betweenness centrality describes the central function an actor has in between two others. Actors with high betweenness centrality often serve as gatekeepers or brokers who connect across scales and levels. Closeness centrality is a measure describing how close actors are to others in the network. Closeness can be important in reacting fast to sudden changes or sudden developments since these actors can quickly take over coordination tasks (Baggio et al. 2010).

Interaction between actors occurs within or across scales, and within or across levels. 'Scale' is understood as the spatial, temporal, quantitative, or analytical dimension used to measure and study phenomena and 'levels' as the units of analysis being located at different positions on a scale (Gibson et al. 2000). A scale-free network has an uneven distribution of links that is not randomized; instead, few highly connected actors exist, while the majority is much less connected. Following Cash et al. (2006), we understand a "scale challenge" as a situation in which the current combination (or lack) of cross-scale and cross-level interactions may harm the resilience of a human-environment system. Ernstson et al. (2010) discuss the crucial network position of scale-crossing brokers in the context of urban ecosystem management: in social networks, brokerage positions emerge that link otherwise disconnected actors, mediating social capital between groups (Burt 2002, 2005). Ernstson et al. (2010) argue that such brokerage positions bridge scales of systems and are crucial to switch between the earlier presented two governance modes of maintaining actor diversity through established ties and initiating effective collective action through the development of fast and more centralized (weak) ties (Ernstson et al. 2010). Governance processes to anticipate gradual changes-such as climate change-require the engagement of diverse actors at different scales that strive to sustain and increase the diversity of actors and links (Olsson et al. 2007). Ernstson et al. (2010) state that it is not the diversity of actor groups that matter most in this context, but the diversity of their interactions with other actor groups and with coupled ecosystems. Brokers become essentially important drivers and controllers, as well as change agents driving innovation and offering a greater range of purposeful collective actions (Ernstson et al. 2010).

Given the mostly positive correlation between density and collaborative processes, a network with many clearly distinguishable dense subgroups and thus less overall cohesion can be seen as problematic for overall collaboration, due to the absence of relational ties between the subgroups (Granovetter 1973). On the other hand, the presence of subgroups is necessary to enhance the development of knowledge and to contribute to the diversity of knowledge, because a constant flux of less relevant information through existing, strong ties may hinder the development and distribution of more specialized knowledge, which is necessary to govern complex systems (Bodin and Crona 2009; Crona and Bodin 2006). The existence of sufficient relational ties across and in between such subgroups is of highest importance, referred to as bridging or weak ties. 
Research gap

Little empirical evidence for this has been published in general, and in an isolated or peripheral community context, especially where social network governance is tied to and strongly dependent on broader ecosystems and physical systems such as climate. Existing social network studies mostly treat network relations as either existing or absent, rarely analyzing structural characteristics and setting them into a resilience context (Bodin and Crona 2009). The mechanisms and practices of switching between governance modes require more research, and more in-depth studies should investigate how the quality and quantity of social ties of different actor groups are interrelated to creating barriers for collective action outside the groups (Ernstson et al. 2010; Duit and Galaz 2008; Duit et al. 2010; Ritter et al. 2002; Wenger 1998).

\section{Empirical analysis}

\section{Research design and goals}

Regional resilience of mountain communities as socioeconomic-ecological systems is related to coping with external stresses such as climate change, by maintaining the stability of its economy while ensuring flexibility for economic innovation and development. The basic goal for this paper is to analyze how the social structure of the tourism governance network in the Gotthard region with the three communities Andermatt, Sedrun, and Disentis relates to resilience to climate change from a quantitative angle.

Following our discussion of socio-ecological networks and resilience, the network governance structure of a community supporting stability but also flexibility is of (1) medium density and (2) of high centralization, has a (3) high cohesion but (4) some subgroups, subgroups which are (5) integrated across scales and levels by brokers or weak ties, and (6) has a high diversity of interactions across scales (Davidson-Hunt 2006; Bodin et al. 2006; Crona and Bodin 2006). The paper follows these six aspects in the analysis of the Gotthard network governance.

The case study region Gotthard-Andermatt-Upper Surselva

The Gotthard-Andermatt-Upper Surselva region (referred to as Gotthard region in the following) has long been neglected by the massive tourism development of the past decades in the surrounding alpine areas. The communities in the region have for a long period of time maintained their traditional way of life based on agricultural activities.
Winter tourism has been playing an important role in supporting local economic development, leading to a high exposure to climate change. Today, the regional economy is dependent on the service sector, of which tourism is the main part (see figure 1 as online resource).

Climate change with warming temperatures and a lack of snow and (foreign) investments in tourism infrastructure in surrounding regions have led to greater sensitivity and to competitive disadvantages of the region. The variability in snow depths and temperatures in winter has been great, and an extremely warm and dry season 2006/2007 (the warmest winter on record according to (Beniston 2007) was followed by an exceptionally snow-rich winter like 2008/2009 (Fig. 1). The long-term trend, however, confirms the rise of average annual temperature for the Alps (IPCC 2007). In a regional Gotthard area context, the snowline has risen by $48.9 \mathrm{~m} /$ decade for the period 1960-2010, while the days with snow cover have been declining by about 10 days/ decade (MeteoSwiss 2011).

The first entries in the ski areas (sold ski tickets) correspond to changes in seasonal weather conditions as do the overnight stays in hotels, confirming the regional vulnerability to direct climate change impacts (Fig. 1). Sudden massive investments in Andermatt, linked to the Andermatt Swiss Alps Resort, have led to further social and economic disparities in this region. External and internal influences have been decreasing resilience of the Surselva region, and the expected future diversification of the population by regional immigration may lead to further community challenges.

The tourism supply chain in the context of resilience

The tourism supply (service) chain is comprised of ten different supply side service provisions, from information and reservation to travel and transportation, food, accommodation, transport inside the destination, sport activities, cultural activities, and departure travel (figure 2 as online resource, Michel 2001).

Adaptation and resilience strategies in tourism demand the contribution and the participation of multiple stakeholders and stakeholder groups throughout the tourism supply chain because of the various dependencies in between them in delivering the service environment for the tourist (Fuchs 2004). Communication between stakeholders, the discussion of common strategies, and the optimization of the supply chain are important for the success of a destination.

Some supply side actors have a very central role in the supply chain. In tourism destinations of the Alps, the cableways companies traditionally have been the main economic drivers and investors (Seilbahnen Österreich 2005). Cableways are the stakeholders suffering most from 
Fig. 1 Average monthly snow depths in the ski areas of the two villages Andermatt and Disentis from 2000 to 2010 (MeteoSwiss 2011). Overnight stays in hotels are the sum of Disentis and Sedrun; first entries are singleday ticket sold by the cableways of Sedrun and Disentis (ClimAlpTour 2011). First entries and overnight stays correspond to seasonal changes in weather patterns, confirming the regional vulnerability to climate change

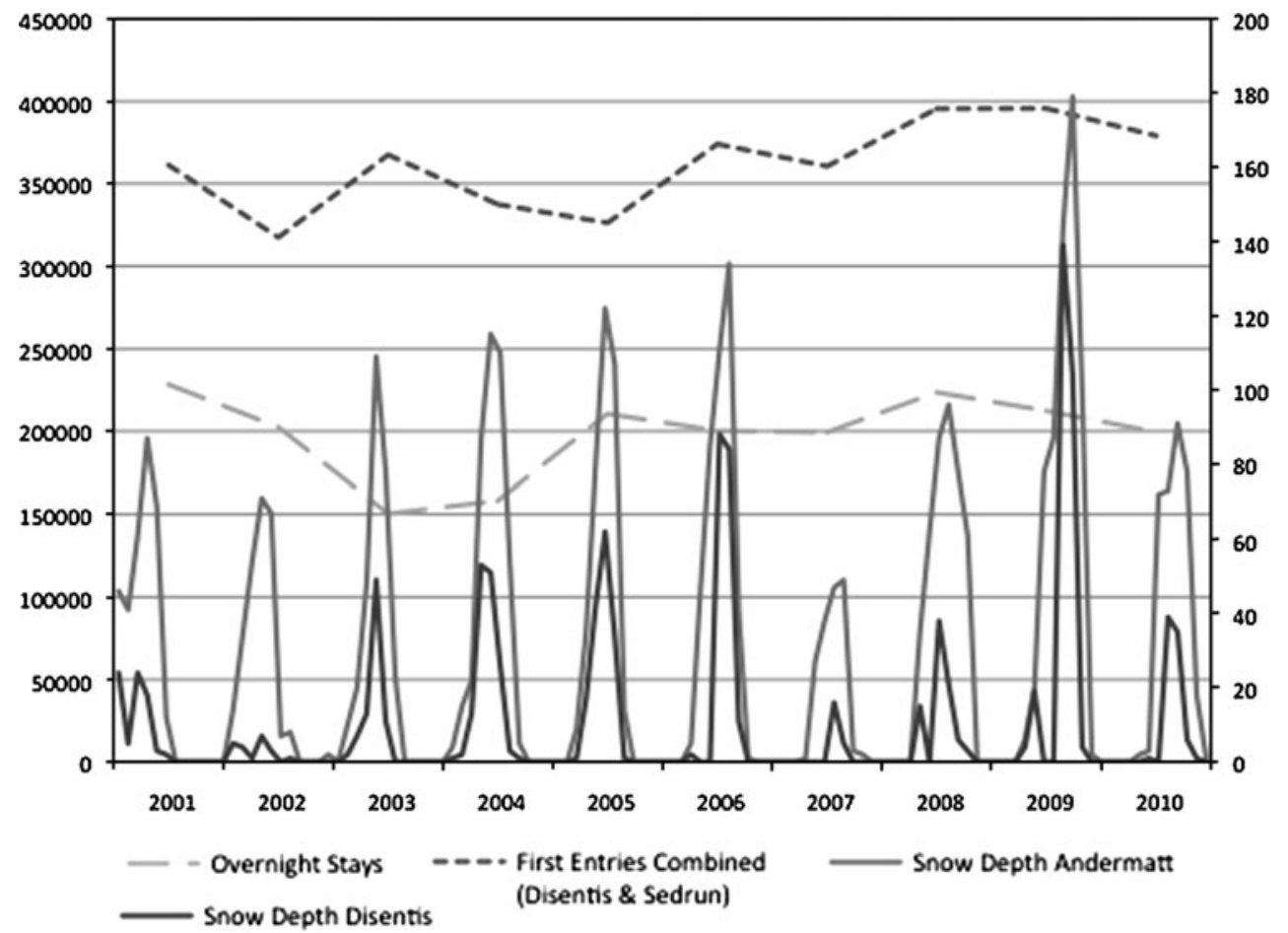

climate change and warming temperatures (OECD 2007; IPCC 2007) due to their high dependency on skiing activities. The growing costs of investments and operations for snow making have to be financed mainly by the cableways companies. However, within the supply chain, they receive only $15-20 \%$ in average of the total spendings generated by tourists (Luthe 2009, see figure 3 as online resource).

This misbalance between risk, service generation, and revenue in the supply chain calls for new forms of cooperation between supply side actors throughout the service change by means of innovations in network governance, developing new ties. Cross-sectoral, bridging connections between the sub-(actor)groups of cableways, hotels, gastronomy, activities, and legal authorities are of major concern for Alpine communities and help foster adaptive capacity to complex problems, such as climate change. Cableways are seeking to better participate in sectors of the supply chain with a higher portion of revenue generation, which in addition are less vulnerable to direct effects of climate change, especially the hotel and gastronomy sectors (Luthe 2009).

Data collection in the Gotthard region

A standardized survey was sent out by mail to all identified stakeholders $(n=170)$ of the tourism supply chain in the Gotthard region, including the villages Disentis, Tujetsch/ Sedrun, Medel, Sumvitg, and Andermatt. The contacts of these stakeholders were provided by the local tourism marketing organizations and verified by an internet desk research. In addition, public authorities (the local municipalities as well as regional public authorities, energy and water providers, forest management, wildlife and hunting) and NGOs (conservation organizations, the Swiss Alpine Club) were included in the survey, because these actors affect the tourism supply chain in a governance context, especially in the sense of developing new services and products that inherently are tied to the natural Alpine environment. The relatively small number of tourism stakeholders in this region allowed for capturing the complete tourism supply chain, comprised of 170 actors.

The actors were asked to send back the anonymous but coded questionnaires in prepaid envelopes within 3 weeks after reception. In the questionnaire, participants were asked whom of the other actors (focusing on the institution, not on individuals) listed they have been in contact with in a professional context. Further questions will be analyzed in forthcoming publications.

\section{Results}

Vertical and horizontal organization of the Gotthard tourism network

The Gotthard tourism supply chain network is organized in an institutional scale with the earlier presented six industry sectors of the tourism supply chain plus a public sector representing individual levels, and in a spatial scale with 
the three main local municipalities as levels (actors from the villages Sumvitg and Medel are included in Disentis due to their geographical closeness and their small total number; Tujetsch/Sedrun is referred to as Sedrun). As integration within the same scale, we find horizontal integration within the same level in both scales and vertical integration between institutional levels. As integration across scales, we find vertical integration within the same institutional level across spatial levels and vertical across institutional levels across spatial levels.

Actors with scale-crossing brokerage function can, for example, be a hotel from Sedrun with a restaurant in Disentis, brokering between the hotel sector in the municipality Sedrun, and the gastronomy sector in Disentis. Following the discussion on the integration of different sectors of the tourism supply chain in the context of diversification and resilience, we specifically seek to identify the integration of the cableways companies as being the major economic drivers and the most vulnerable to climate change in such winter tourism destinations. Their vertical local integration and their scale-crossing function across villages will be identified in this SNA.

\section{Sample description}

The SNA data of this case study were analyzed with the programs Visone (visualization of social networks, http://www.visone.info) and Gephi (http://www.gephi.org). The participation rate of about $42 \%(N=71$, Table 1$)$ was achieved after reminding phone calls to those who did not reply within the first deadline. Reasons for not responding were either non-reachability, a lack of time, or, mostly, no willingness to provide information due to lack of trust to competitors or to the political and legal side, although the questionnaire was anonymously coded. From the $n=170$ actors, the participating $N=71$ actors named links to 159 actors; 11 actors have no connections with the 71 respondents.

Table 1 Participation rates of the SNA of the Gotthard tourism supply chain

\begin{tabular}{llccc}
\hline $\begin{array}{l}\text { Sectors } \\
\text { (subgroups) }\end{array}$ & $\begin{array}{l}\text { Sector } \\
\text { number }\end{array}$ & Questionnaires & $\begin{array}{l}\text { Valid } \\
\text { responses }\end{array}$ & $\begin{array}{l}\text { Response } \\
\text { rate }(\%)\end{array}$ \\
\hline Accommodation & 1 & 50 & 21 & 42.0 \\
Gastronomy & 2 & 41 & 11 & 26.8 \\
Entertainment & 3 & 5 & 0 & 0.0 \\
Transport & 4 & 9 & 5 & 55.6 \\
Activities & 5 & 41 & 20 & 48.8 \\
Information & 6 & 2 & 2 & 100.0 \\
Public actors & 7 & 22 & 12 & 54.5 \\
Total & & 170 & 71 & 41.8 \\
\hline
\end{tabular}

As with all empirical estimations, a sample is only a partial representation of the broader social reality (Baggio and Klobas 2011; Baggio et al. 2010). In contrast to representative sampling in other contexts, the scale-free characteristics of most networks (social and natural) lead to a number of crucial points that must be taken into account when generalizing the insights derived from the sample, of which we present two most relevant ones for this study:

1. The possibility of omitting hubs, fundamentally changing the characteristics of the described network.

2. The overrepresentation of actors with certain connectivity characteristics, for example the upper tier of actors with the biggest numbers of connections due to a higher "visibility".

These aspects call for a careful application of statistical methods and insights derived from there, due to the possibility of a limited representativeness of the sample. In the case at hand, a qualitative evaluation of the network has been conducted alongside the quantitative investigation (Schneider 2011). Twenty-two actors were selected by their betweenness centrality, including high, middle, and low degrees within each of the six industry sectors plus the public sector where applicable (some sectors had only actors with $0^{\circ}$ ) and one isolate. These actors were interviewed to validate the initial written SNA questionnaires they filled out and to evaluate their individual feelings about their network position and possible reasons for their identified position; these results confirm the quality of the questionnaire results and the representativeness of the sample for the whole regional network and will be published in a following paper.

\section{Network density and centrality}

With a total number of 1,814 links, the network has a rather low density of $7.2 \%$. The distribution of links and degrees in the network is very uneven as typical for a scale-free network; few highly connected actors exist, while the majority is much less connected. From the total sample of $n=170$ actors, 11 actors are not connected. From the 159 actors (100\%) with a total of 1814 links between each other $(100 \%)$, only three actors $(1.8 \%)$ together have 477 links or $26 \%$ of the total connected to and from them. The 20 most central actors (12\%) have 1,427 links connected to and from them $(78 \%)$, forming a highly central core group in the network. This uneven distribution of links makes the tourism supply chain of the Gotthard region a centralized network with a clear power distribution between a centralized core and a less connected peripheral network. Figure 4 (online resource) visualizes the uneven distribution of links with the actors on the horizontal axis and the number of links on the vertical axis, indicating a power-law 
distribution in a scale-free network where few actors share the most links, while the majority of actors has few links.

When visualizing the link distribution on a log-log chart with both the $x$ - and $y$-axis logarithmized, one would expect a linear exponent of the graph as a clear power tail. In the Gotthard network, the major part of the graph converges asymptotically a linear exponent with a slope $m=-0.9$, apart from the lower tale, indicating a disproportionally low number of ties at the bottom end of the curve (Fig. 2). In this log-log graph, there is a change in the exponent before the upper tale of the function visible (a step), indicating a disproportionally low number of ties around the core actors. This confirms a core-peripheral network with a specifically high number of poorly connected actors in the periphery of the network, even though a certain lack of links in the core part of the core exists.

Network modularity, clustering, and cohesion

We compute a randomized version of the network as a null model to assess the extent of modularization and compare this stochastic algorithm-representing the self-organizing network properties-with the predefined sectors and locations.

The modularity coefficients of the predefined supply chain sectors 1-6 and the locations $1-4$ (for a legend see Fig. 3) are shown in Table 2, as well as the modularity of the null model with 0.315. Apart from sectors 1, 2, and 5, all other sector and location values are lower than the coefficient of the reference model. Sector 1 has an equal value; the two sectors gastronomy (2) and activities (5) each have a higher value and may thus count as existing, denser modules within the network. Thus, from the predefined modules or subgroups, quantitative modularity analysis confirms the existence of two subgroups in the network.

The average clustering coefficient of the network is 0.435 . This is low given the theoretically possible maximum coefficient of 1 a graph can have, but high compared to the average clustering coefficient of 0.224 of a randomized version of this graph, based on the randomized connections of all given nodes with a probability of $5 \%$. This makes the graph a small-world graph.

Figure 3 shows the Gotthard tourism supply chain network as a whole. Actors are distinguished by sector in their shapes and by location in their colors (see the legend in Fig. 4). The cohesive Gotthard network lacks clearly distinguishable subgroups. The network has a rather low density and thus a lower potential for collaborative action. However, there is a centralized core of actors with high degree centrality and a large number of actors at the outer rim of the network with ties mostly toward the center, but few to other actors with lower centrality.

In the next step, we analyze the integration of the most central subnetwork with the remaining network, which shall reveal the overall cohesion.

When deleting all ties of the network that are not existing in between the 20 actors with highest betweenness centrality, we find a subnetwork without any clearly distinguishable subgroups and again a high cohesiveness (Fig. 5).

Inverting the tie selection by deleting all connections in between the 20 most central actors, we find again a quite cohesive network of the remaining 139 actors without clearly distinguishable subgroups. Only the lower part of the network shows a denser concentration of ties within the hotel sector of Disentis, which are still well connected with the remaining actors (Fig. 6). The separated analysis of the
Fig. 2 Network centrality of the Gotthard tourism supply chain network in a log-log chart, indicating an average slope of $m=-0.9$ in the central part, and a disproportionally low number of ties at the bottom of the curve, as well as around the core actors before the upper tale of the curve

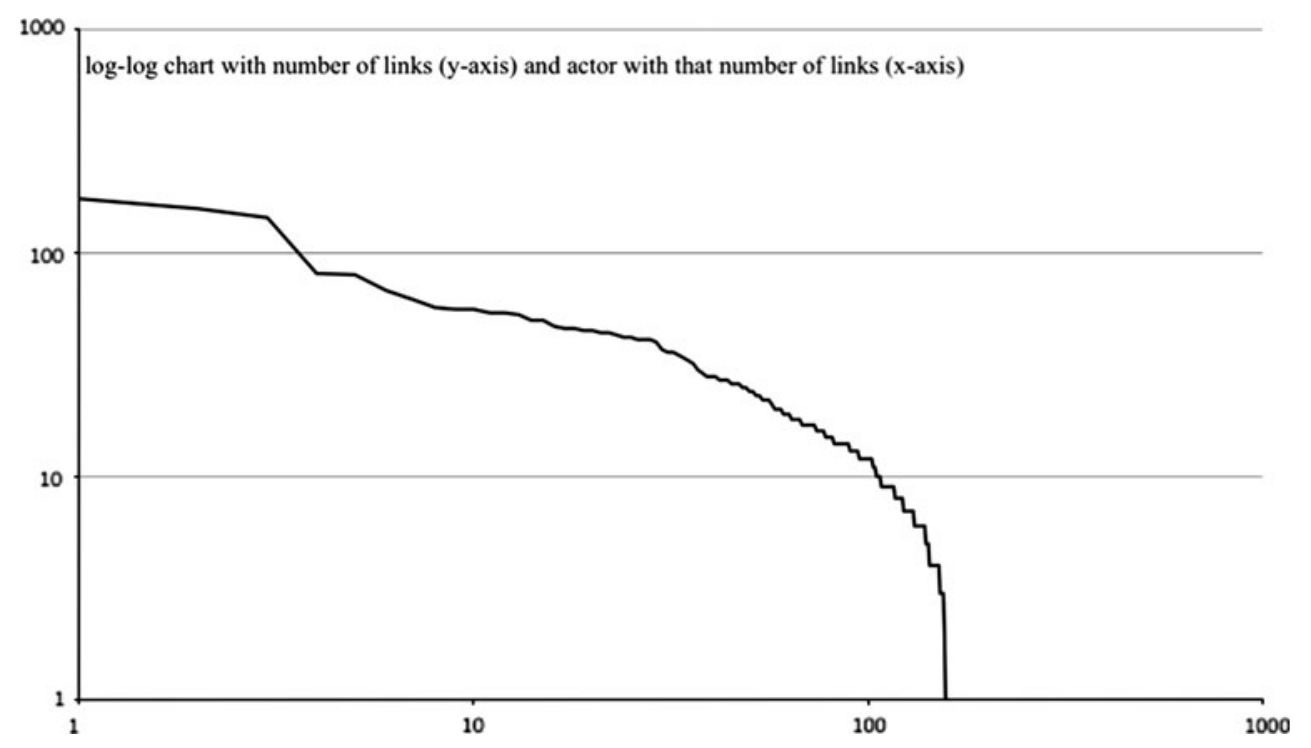




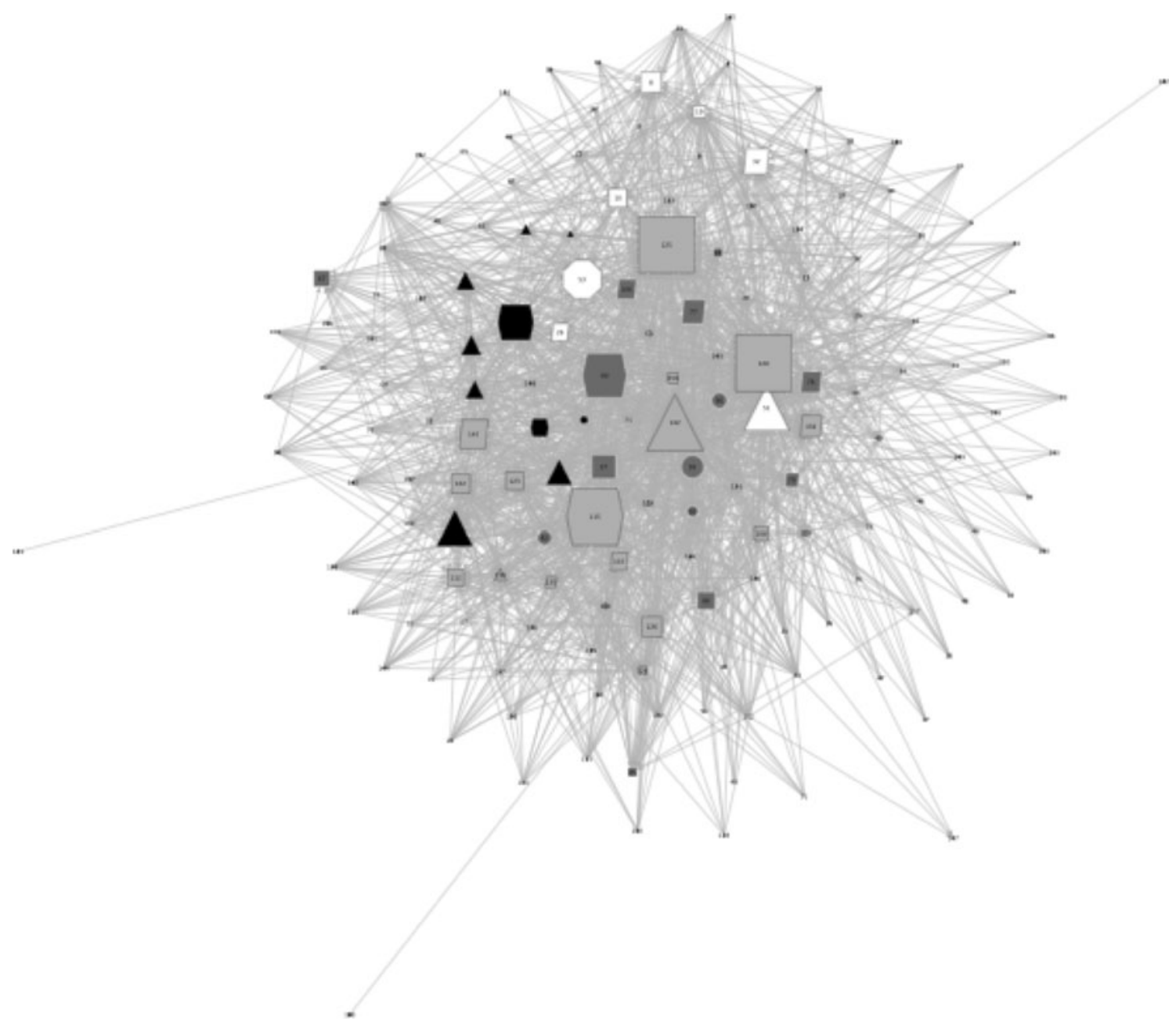

Fig. 3 Complete network of the Gotthard region tourism supply chain in three main municipalities Andermatt, Disentis, and Sedrun (including the small villages Sumvitg and Medel), and regional actors

Table 2 Modularity coefficients for the predefined modules of sectors and locations and of a randomized null model

Sectors 2 (gastronomy) and 5 (activities) have a higher value than the reference and are thus confirmed subgroups

\begin{tabular}{ll}
\hline Sector & Modularity \\
\hline 1 & 0.315 \\
2 & 0.467 \\
3 & No \\
& connections \\
4 & 0 \\
5 & 0.361 \\
6 & 0 \\
Location & \\
1 & 0 \\
2 & -0.015 \\
3 & -0.006 \\
4 & 0.173 \\
Reference & 0.315 \\
(randomized & \\
null model) & \\
\hline
\end{tabular}

(locations indicated by gray tone scales). The size of the actors indicates their betweenness centrality, and the shapes indicate the six supply chain sectors plus the public sector

most central actors and the other actors confirms a cohesive network with a central cohesive inner network and a less central but cohesive outer network.

Figure 5 (online resource) shows the whole network with the most central 20 actor subnetworks (black ties on the right side) manually separated from the remaining network (black ties on the left side). Both subnetworks are cohesive and interconnected (gray ties), confirming the overall cohesion and centralized character of the Gotthard network.

Scale-crossing dynamics on an individual actor level: the spatial and the institutional scales

When manually separating the spatial scale in the three municipalities of Andermatt, Disentis, and Sedrun in three subgroups, we can identify differences in the vertical 


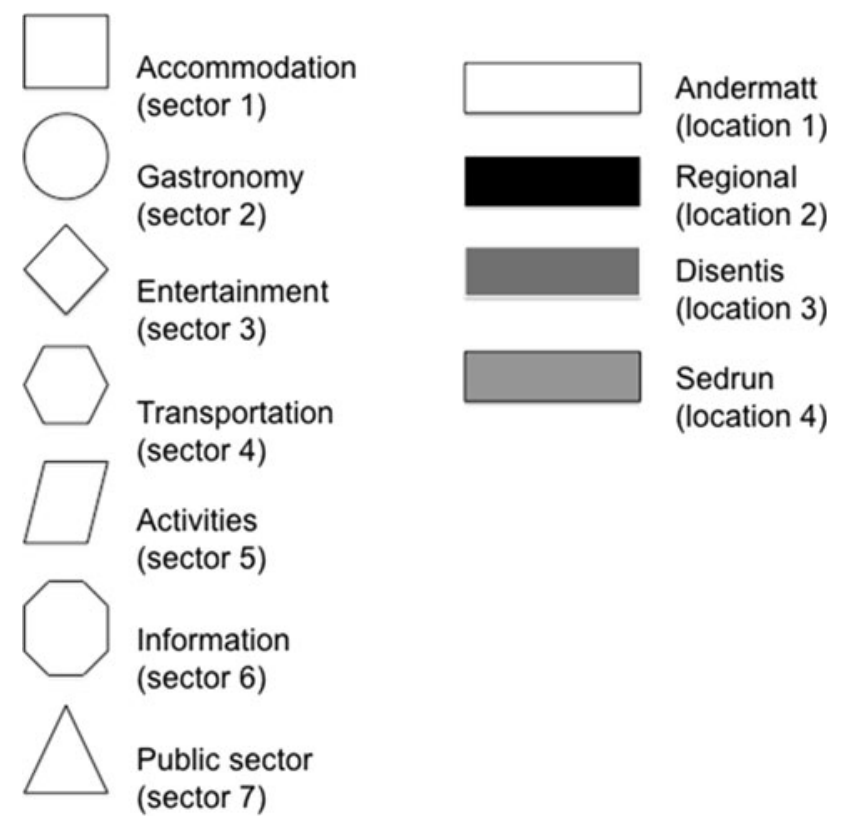

Fig. 4 Legend of the network graphs with the institutional scale of the six tourism sectors plus the public sector and the spatial scale with the three villages plus a regional level

spatial integration (Fig. 7). Andermatt (white shapes on the upper right) is highly connected with Sedrun (gray shapes with black frames on the left), as Sedrun is with Disentis (gray shapes with white frames on the right). Andermatt and Disentis are not very integrated; two actors from Andermatt account for the majority of existing ties to Disentis, taking over a scale-crossing brokerage function as we outline in the individual actor analysis paragraph. Given the overall regional network density of $7.2 \%$ and the relatively high densities of the communities (Sedrun 17\%, Disentis 15\%, Andermatt 10\%), we conclude that the spatial integration between the communities has a high effect on the overall density.

Institutional scale integration of the tourism supply chain and public actors

Figure 6 (online resource) shows the Gotthard tourism network with the six service supply chain sectors manually separated, but without spatial separation. Most sectors are horizontally and vertically integrated with and in between each other. The entertainment sector [small dots at about $100^{\circ}$ angle in figure 6 (online resource)] with overall fewer ties due to the smaller number of actors are more isolated than the other sectors. The entertainment sector (3) lacks connections to sectors 4 (transportation) and 6 (information).

Regional political and legal actors are well integrated, horizontally and vertically with the tourism supply chain, given their more additional and indirect functionality in a tourism supply chain context. The regional authority for Surselva based on the cantonal capital of Chur has the highest centrality of this sector.

Actor centrality and gatekeepers

Looking at the network structure on the individual actor level, we analyze and compare various centrality measures. Table 3 shows the ten most central actors of the Gotthard tourism network by three kinds of centrality degrees. The four most degree-central actors are all from Sedrun with the municipality, two hotels and the regional train company. No regional actor (regional level 2) is within the ten most central actors, but from all other spatial-jurisdictional levels.

In betweenness centrality, the first five positions are the same (apart from the two hotels on positions 2 and 3 that swapped) as in degree centrality; in the last five positions, there are three new actors including the tourism organization of Andermatt (actor ID 53), the regional political actor Region Surselva (104), and the Sedrun Golfclub (145). These ten actors are the main gatekeepers of the network.

Closeness in the Gotthard network has a different structure than degree and betweenness; political and legal actors are of higher centrality in regards to closeness. The three cableways of the three municipalities have the highest closeness centrality, followed by the regional train company and the tourism marketing organization of Switzerland. The political actor Region Surselva and the municipalities of Disentis and Andermatt are as well within the first ten closest actors. Despite the clear scale-crossing broker function of the Andermatt cableways, they are not a gatekeeper by betweenness centrality definition (126th position in betweenness centrality).

Variety of centrality degrees

As shown in Table 4, there are centrality differences between betweenness and degree and the closeness measures. Furthermore, there is a great variety of centrality measures within and in between the levels of the scales, increasing the variety of ties between actors.

Tables 4 and 5 show the variety of centrality degrees across network members. Table 4 shows the institutional sector-based betweenness centrality with a large variety of degrees between the five most central actors per sector and a large variety of locations per sector. Similar differences can be found in the spatial scale of the five most central actors per village; there is a great variety of sectors per location (Table 5). Apart from sector three, we find ranges from high to low centrality percentages in all levels of both scales. 


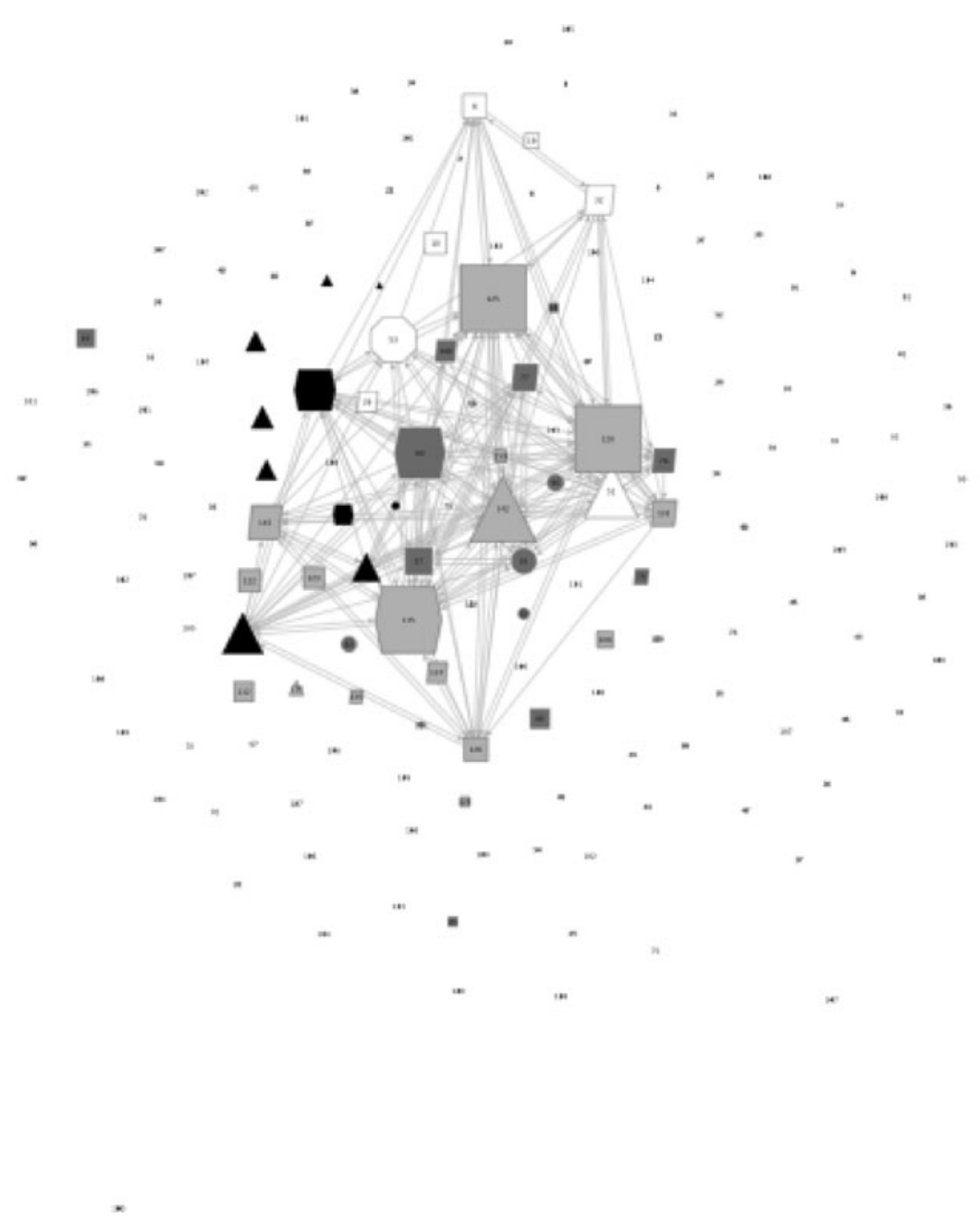

Fig. 5 Core of the Gotthard tourism supply chain network showing only ties in between the 20 most central actors

\section{Summary}

The scale-free Gotthard tourism supply chain network is cohesive and centralized, without the expected supply chain sectors and municipalities as distinguishable subgroups; only the gastronomy and the activity sector make an exception and show a higher modularity coefficient than the randomized reference.

It is a small-world graph where most nodes are not neighbors but can be reached from every other by a small number of steps.

The regional network is not very dense with $7.2 \%$. The densities within the communities are higher, so the spatial integration between the communities is rather low. The centralized core of the network with about 20 actors is well integrated with the rest of the actors in the network, which in itself is cohesive.

The variety and diversity of connections is high as the overall vertical and horizontal integration within, between, and across scales and levels is given, apart from the spatial integration between Andermatt and Disentis.

The tourism supply chain is vertically and horizontally integrated, with obvious exceptions of the gastronomy sector in Andermatt and Sedrun (though it is highly important within the tourism value chain) and the entertainment sector and the municipality in Disentis. The most central actors and gatekeepers are in the village of Sedrun, from the public, the hotel, and the information sectors. The cableways of Sedrun and Disentis are of high degree and betweenness centrality, whereas the cableways of Andermatt are not. In closeness centrality, all cableways are of high relevance.

On the spatial scale, we find a clear lack of integration between the municipalities of Andermatt and Disentis, while tourism actors in Sedrun are well connected to actors in both Disentis and Andermatt, serving as brokers between the villages. These brokers with highest betweenness centrality are the municipality, two hotels, and the cableways. 


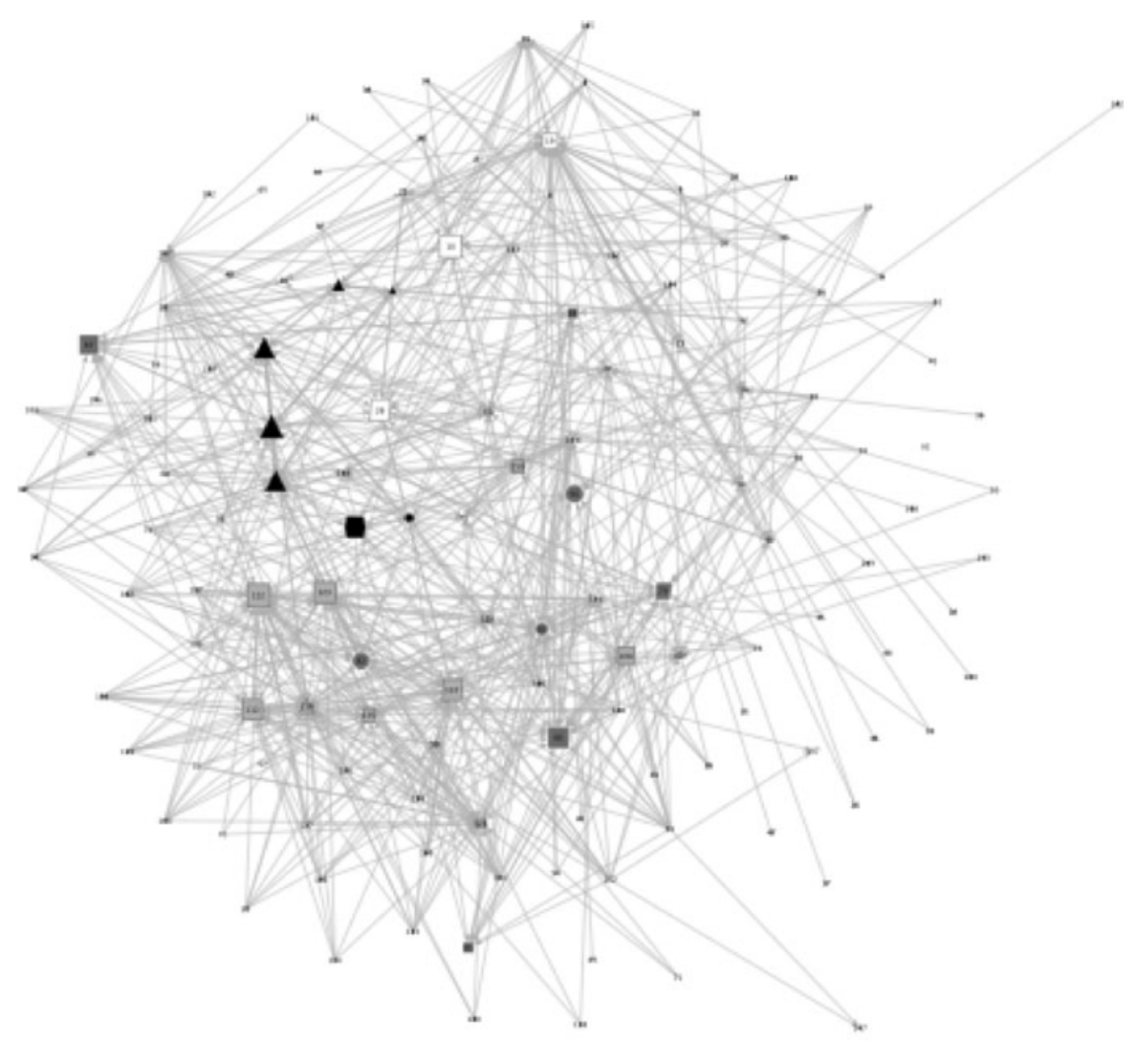

Fig. 6 Peripheral part of the Gotthard tourism supply chain network with the 20 most central actors and the ties in between deleted, indicating the low density of ties in between them, referring to the log-log chart of Fig. 2

The Andermatt cableways take not the expected gatekeeper function due to their low betweenness centrality but have a brokerage function with Disentis, mainly via the Disentis cableways.

The variety of centrality degrees accounts for a resilient structure of this regional network, because it supports the occurrence of various kinds of ties between actors. Degrees span from higher than 21 down to zero with variations in actor positions by betweenness, degree and closeness centrality, varied on the institutional level (sectors 1-6 plus the public sector are spread over the whole span of centrality measures) and on the spatial level (the three locations are well distributed over the whole range of centralities).

\section{Discussion}

The overall well-integrated tourism supply chain of the Gotthard network is in line with the theory suggesting that actors along the supply chain should ideally be well connected for being most resilient (Fuchs 2004). In practice, the main economic drivers of Alpine winter tourism destinations, the cableways, are often not sufficiently integrated with other actors such as the hotel and gastronomy sector, leading to the described inequalities in investments, risk management, and revenue generation. The identified subgroups gastronomy and activities are lacking a more central integration within the supply chain despite the overall cohesiveness of the network. From a climate change resilience perspective, especially the sectors transportation, accommodation, and gastronomy, which jointly generate the highest share in revenue in tourism, should collaborate very closely in order to spread investment risks and revenue and to innovate in new products and snow-independent packages. Since gastronomy is a subgroup with a higher modularity, collaboration should be specifically improved between this sector and the network. 


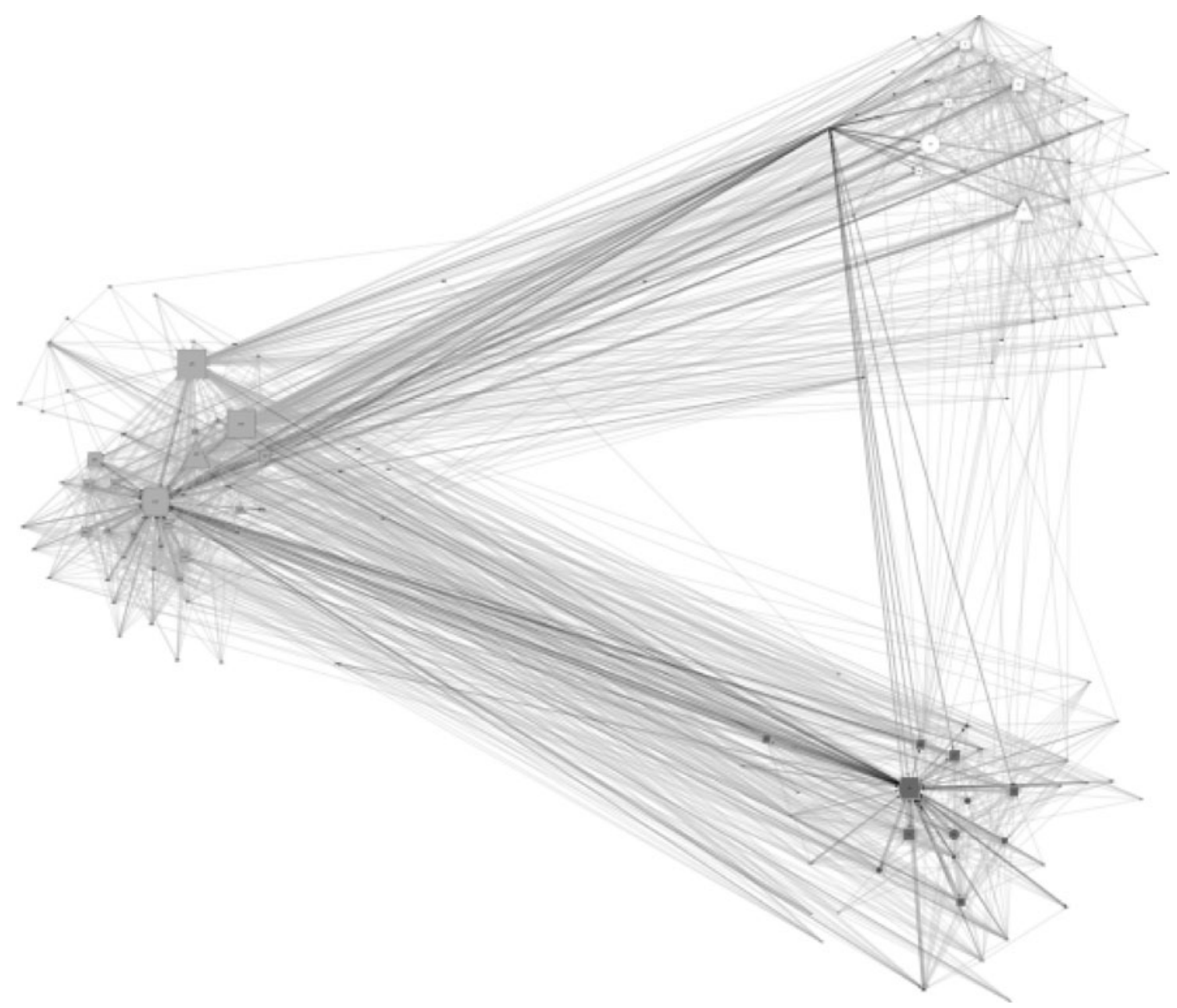

Fig. 7 The Gotthard tourism supply chain network manually separated by the three locations Andermatt (upper right), Disentis (lower right), and Sedrun (upper left). Gray lines indicate all ties between actors, and black lines indicate ego-networks of the three cableways in the three municipalities. Andermatt (top right) and Disentis (bottom

As expected, the cableways as the main economic drivers are highly central gatekeepers in Disentis and Sedrun. In Andermatt, they are of very low degree and betweenness centrality, but all cableways are of high closeness centrality. Since closeness is of relevance for reacting fast to sudden changes, this centrality measure can be of importance for resilience in the region to immediate shocks and fast variations of climate change, such as storms or extremely warm and dry winters. For describing resilience to the generally rather slow developing impacts of climate change over a longer period, degree centrality may be of higher importance, since actors with high degree centrality can better steer diversification from winter tourism and actively drive innovation.

Based on the insights from the network literature, new ties would support learning of networks and innovation, both being of highest relevance for diversification and thus resilience in the region. The establishment of new ties right) are poorly integrated which Sedrun taking a brokerage function between both villages. The cableways of Andermatt have a lower betweenness centrality than expected given their important economic function in the tourism governance system

between the sectors transportation, accommodation, and gastronomy is important, but despite their lower economic importance and overall centrality, other sectors and actor groups such as the activity and entertainment sector should be connected more as well, in order to bring in new ideas and support innovation in new products.

Bodin and Crona (2009) present some archetypical network typologies of which there is type A with highest cohesiveness but no subgroups and type $\mathrm{C}$, which is highly centralized and less cohesive.

Bodin and Crona (2009) point out that highly cohesive networks (Fig. 8a) tend to be better adapted to cope with not clearly defined external pressures such as climate change based on the high capacity of its members to engage in collaborative processes, among others due to the shared (tacit) knowledgebase. In contrast, highly centralized networks (Fig. 8c) are more adept for the solution of clearly delimited challenges, which call for a prompt and 


\begin{tabular}{|c|c|c|c|c|c|c|c|c|c|c|c|c|c|c|}
\hline & & $\Xi$ & & 节 & 产 & & & & 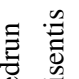 & $\Xi$ & $\begin{array}{l}\text { Table } \\
\text { highest }\end{array}$ & $\begin{array}{l}\text { ennes } \\
\text { per se }\end{array}$ & $\begin{array}{l}\text { ty degree variation } \\
\text { he institutional scal }\end{array}$ & $y$ the five \\
\hline & & $\begin{array}{l}\vec{Z} \\
\tilde{D} \\
\tilde{n}\end{array}$ &. $\mathscr{0}$ & 宼 & రే & $\stackrel{\stackrel{N}{*}}{\frac{N}{3}}$ & $\sum_{0}^{\infty}$ & 节 & $\begin{array}{ll}\infty & \overline{0} \\
\geq & 2\end{array}$ & ت्己 & Sector & Id & Betweenness (\%) & Location \\
\hline & Е్ & స్తn & $\sum_{\overrightarrow{3}}^{\infty}$ & $\overbrace{\substack{\mathrm{d} \\
3}}^{\infty}$ & $\bar{E}$ & \& & $\vec{E}$ & $\begin{array}{l}\Xi \\
\Xi\end{array}$ & & ర్ & 1 & 120 & 10.30491651 & 4 \\
\hline & $\frac{\overline{0}}{0}$ & $\frac{\overrightarrow{0}}{\frac{\pi}{\pi}}$ & $\frac{\overrightarrow{0}}{\frac{\pi}{\pi}}$ & $\begin{array}{l}\frac{3}{0} \\
\frac{0}{\pi}\end{array}$ & $\frac{\ddots}{7}$ & $\stackrel{n}{\Xi}$ & $\frac{\overline{0}}{0}$ & . & $\stackrel{\varrho}{\Xi}$ & $\begin{array}{l}\text { Dै } \\
\text { 吾 }\end{array}$ & 1 & 125 & 8.102496785 & 4 \\
\hline & & & 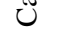 & $\tilde{U}$ & & 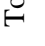 & & $\overline{0}$ & $\Sigma \Sigma$ & $\ddot{\varphi}$ & 1 & 57 & 1.512018607 & 1 \\
\hline & & & & & & & & & & & 1 & 8 & 1.130580296 & 1 \\
\hline & 프 & $\stackrel{n}{=}$ & $\infty$ & $\stackrel{\infty}{\sim}$ & in & $\underset{0}{0}$ & $\underline{\theta}$ & ô & I & 导 & 1 & 126 & 1.100812843 & 4 \\
\hline & & & & & & & & & & & 2 & 93 & 1.347777064 & 3 \\
\hline & & & & & & & & & & & 2 & 96 & 0.603837614 & 3 \\
\hline : & $\frac{0}{00} \frac{0}{\pi}$ & & & & & & & & & & 2 & 82 & 0.542652501 & 3 \\
\hline ह & $\underline{w}$ & $\checkmark$ & $m$ & - & N & 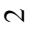 & $N$ & $m$ & $\nabla m$ & $\nabla$ & 2 & 92 & 0.301409872 & 3 \\
\hline$n$ & & & & & & & & & & & 2 & 36 & 0.075799448 & 1 \\
\hline$D_{0}$ & 营。 & & & & & & & & & & 3 & 81 & 0 & 3 \\
\hline 0 & ల్ల & $\nabla$ & A & ナ & $\checkmark$ & $\Lambda$ & N & $n$ & $r-$ & $n$ & 3 & 35 & 0 & 1 \\
\hline & & & & & & & & & & & 3 & 41 & 0 & 1 \\
\hline & & & & & & 䲶 & & & & & 3 & 49 & 0 & 1 \\
\hline & & $\Xi$ & & & $=$ & (2) & 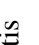 & $\equiv$ & हิ & & 3 & 40 & 0 & 1 \\
\hline & & $\overline{0}$ & & & $E$ & 䒺 & ల్ల & $\ddot{Z}$ & छิ & $\Xi$ & 4 & 115 & 7.459984779 & 4 \\
\hline & & $\gtrsim$ & $\Xi$ & $\Xi$ & $\infty$ & $\geqq$ & 0 & है & $\begin{array}{l}0 . \bar{D} \\
=\end{array}$ & Ë & 4 & 80 & 5.239585196 & 3 \\
\hline & త్ & : & 苟 & हై & 死 &. & $\overbrace{3}^{2}$ & 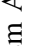 & $\vec{\Xi} \tilde{\Xi}$ & 三 & 4 & 55 & 3.263815343 & 1 \\
\hline & $\bar{g}$ & $\stackrel{\tilde{U}}{\Xi}$ & $\bar{D}$ & $\overline{0}$ & $\frac{2}{0}$ & 离 & $\frac{2}{0}$ & $\overrightarrow{\bar{\Xi}}$ & $\frac{0}{0} \cdot \frac{0}{60}$ & $\begin{array}{l}\bar{U} \\
\pm\end{array}$ & 4 & 105 & 0.772212869 & 2 \\
\hline & 希 & $\dot{\Sigma}$ & 온 & 番 & U & $\Sigma$ & U & $\Leftrightarrow$ & $\bar{\Xi} \approx$ & ڤ̊ & 4 & 64 & 0.083619348 & 2 \\
\hline & & & & & & & & & & & 5 & 145 & 2.249727636 & 4 \\
\hline & $\Xi$ & I & తి & $\stackrel{\beth}{\simeq}$ & $\stackrel{n}{=}$ & $\bar{n}$ & $\infty$ & $n$ & $n \subseteq$ & Ð & 5 & 32 & 1.766561153 & 1 \\
\hline & & & & & & & & & & & 5 & 77 & 1.506066176 & 3 \\
\hline 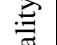 & & & & & & & & & & & 5 & 132 & 1.317744272 & 4 \\
\hline 壳 & $\cdot \overline{0} \frac{0}{\sigma}$ & & & & & & & & & & 5 & 76 & 1.200963651 & 3 \\
\hline$n$ & $\approx \tilde{w}$ & $\nabla$ & ナ & $\forall$ & $\checkmark$ & - & $m$ & - & $\mathrm{N} N$ & $\nabla$ & 6 & 53 & 4.016098628 & 1 \\
\hline$\stackrel{\Xi}{\Xi}$ & & & & & & & & & & & 6 & 143 & 0 & 4 \\
\hline$\overline{\overrightarrow{0}}$ & 苟 0 & & & & & & & & & & 7 & 142 & 21.59298659 & 4 \\
\hline $\begin{array}{c}2 \\
0 \\
0\end{array}$ & 式 & & - & - & + & 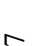 & + & b & + & ๑ & 7 & 51 & 5.510221049 & 1 \\
\hline & & & & & & & & & & & 7 & 104 & 3.250632387 & 2 \\
\hline & & & & & & E्ञ & & & & Е & 7 & 60 & 1.55958334 & 2 \\
\hline & & $\Xi$ & & & $=$ & ] & $\mathscr{\Xi}$ & & ‡્ & है & 7 & 63 & 0.964631212 & 2 \\
\hline
\end{tabular}

simple solution. As soon as the external challenge becomes more complex-with less clearly understood effects upon the local system - centralization can be a hindering factor to innovation and the implementation of novel solutions. We find a mixed or combined type in the Gotthard network that is both cohesive and still centralized.

Additionally, the Gotthard tourism network follows a center-periphery structure, with a small number of highly interconnected central actors and many peripheral actors that are mainly connected to those central actors, but to a lower extent with each other.

From a governance and climate change adaptation perspective, the well-connected core of the network will be able to initiate and execute change-oriented initiatives such as adaptation to climate change by economic 
Table 5 Betweenness centrality degree variation sorted by the five highest degrees per location on the spatial scale

\begin{tabular}{lccl}
\hline Location & Id & Betweenness $(\%)$ & Sector \\
\hline 1 & 51 & 5.510221049 & 7 \\
1 & 53 & 4.016098628 & 6 \\
1 & 55 & 3.263815343 & 4 \\
1 & 32 & 1.766561153 & 5 \\
1 & 57 & 1.512018607 & 1 \\
3 & 80 & 5.239585196 & 4 \\
3 & 77 & 1.506066176 & 5 \\
3 & 93 & 1.347777064 & 2 \\
3 & 76 & 1.200963651 & 5 \\
3 & 106 & 1.025723037 & 5 \\
4 & 142 & 21.59298659 & 7 \\
4 & 120 & 10.30491651 & 1 \\
4 & 125 & 8.102496785 & 1 \\
4 & 115 & 7.459984779 & 4 \\
4 & 145 & 2.249727636 & 5 \\
\hline
\end{tabular}

(A)

(B)

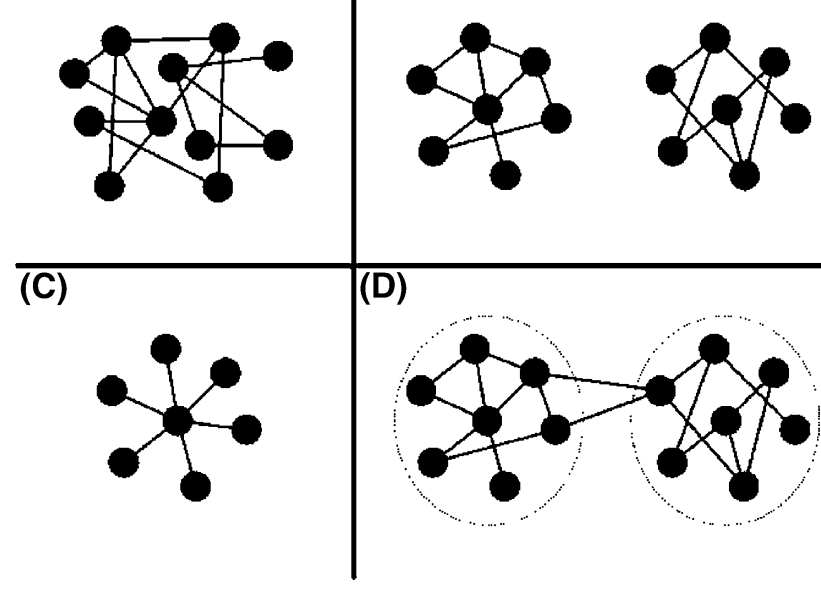

Fig. 8 Network typologies adapted from Bodin and Crona (2009)

diversification and innovation in snow-independent tourism products. The peripheral core with a lower density of links between those actors could lead to a limited variety of ideas that are considered within the governance system at stake (compare with Cooper et al. 2009) and thus result in a limited innovative capacity for economic diversification and resilience.

In addition, change-oriented initiatives that are not supported by the relatively small number of actors taking the role of gatekeepers, or even worse, if innovative new ideas coming from peripheral actors are turned down by the (group of) central actors, they will most likely not be implemented in the region (Dawley et al. 2010). This is exactly the case in the Gotthard region, where more peripheral actors who visited participatory workshops (as held in the ClimAlpTour project, ClimAlpTour 2011) reported that their ideas for product innovation were turned down by the central actors network. This unbalanced distribution of power within the local network can have substantial influences upon adaptation processes in the region, leading to rather conventional decision-making patterns with a concentration on existing strengths and finally a situation of lock-in (Grabher 1993; Martin and Sunley 2006). We can confirm this mechanism and a lock-in effect with the situation reported from the regional adaptation workshops (ClimAlpTour 2011).

In order to allow for innovative processes to take place within the tourism system, it is important to a) have diversified connections within the system and beyond and b) to let information on possible innovation measures circulate among the highest number of possible actors within the network. While we cannot quantify the diversity of connections from the analysis of this paper, we can state that a network with a center-periphery characteristic is counterproductive to maximize communication between the actors (=a balance of power within the network governance structure) and therefore to the endogenous innovative capacity of the network in the face of external pressures, such as climate change (see e.g. Cote and Nightingale 2011; Adger et al. 2009). The process of innovation and the generation of new ideas, and how these ideas are entering the power steering part of the network, are subject to further research.

\section{Conclusions}

With respect to the broader debate on resilience of social systems toward external pressures, as for example those related to climate change, the present study offers an empirically underpinned estimation of the governancelinked resilience of the Gotthard tourism system by making use of a network-based approach.

In the Gotthard tourism supply chain network, we find evidence for both a high and a low resilience network structure, with a tendency toward higher resilience. The low network density is a structural weakness because it compromises collaboration by lack of ties. The network has strengths in coordination and collective action due to its high centralization but could exhibit problems in solving more complex problems related to the uncertainty of regional climate change impacts through an uneven distribution of power and influence due to the core-periphery structure of the network. The small-world character of the graph supports resilience due to its higher effectiveness in processing information by filtering to highly central nodes, while keeping the number of links required connecting all the actors of the network to a minimum. 
The high cohesion of the network with only two subgroups enhances resilience through close collaboration between actors, but may have negative effects on the innovation capacity of the network, depending on how and where new ideas are generated and how they enter the system. Innovation may collaboratively develop and mainly enter the system from the existing two subgroups.

The overall well-integrated tourism supply chain with a high diversity of links has weaknesses in the integration of the less central gastronomy sector in Sedrun and Andermatt and of the more isolated entertainment sector. In addition, from a geographical perspective, the actors of Andermatt and Disentis generally lack integration between the two municipalities.

The structural weaknesses of the analyzed network lead to a scale challenge where the lack of cross-scale and crosslevel integration needs to be overcome by the development of new ties with those actors that are more isolated. Identified gatekeepers and brokers could take over this task. In addition, a broker from outside the network could possibly enable the building of new ties more effectively.

Further research is required in order to generalize the results of this study to the broader regional economy of the Gotthard region and to take into account more complex interrelated socio-economic changes in the region. A further promising line of research would be to complement the network with connections reaching beyond the region to allow for a better generalization of the results. In addition, it will be important to further investigate the qualitative characteristics of the network connections between actors in order to provide policy makers and the broader public with more detailed information on how to increase the resilience linked to climate change adaptation in the region. A comparison of this network with networks of different regions might offer additional insights in mechanisms of network governance functions related to climate change and resilience.

Acknowledgments We woud like to acknowledge the project funding by EU Interreg ClimAlpTour and by Swiss Network of International Studies (SNIS), as well as to support by Ulrik Brandes and Bobo Nick, University of Konstanz.

\section{References}

Adger WN (2000) Social and ecological resilience: are they related? Prog Hum Geogr 24(3):347-364

Adger W, Dessai S, Goulden M, Hulme M, Lorenzoni I, Nelson D, Naess L, Wolf J, Wreford A (2009) Are there social limits to adaptation to climate change? Clim Chang 93(3):335-354

Baggio R (2011) Collaboration and cooperation in a tourism destination: a network science approach. Curr Iss Tour 14(2): 183-189

Baggio R, Klobas J (2011) Quantitative methods in tourism: a handbook, vol 48. Channel View Books, Bristol
Baggio R, Scott N, Cooper C (2010) Improving tourism destination governance: a complexity science approach. Tour Rev 65(4):51-60

Beniston M (2007) Entering into the "greenhouse century": recent record temperatures in Switzerland are comparable to the upper temperature quantiles in a greenhouse climate. Geophys Res Lett 34(L16710):5

Bodin Ö, Crona B (2009) The role of social networks in natural resource governance: what relational patterns make a difference? Glob Env Chang 19(3):366-374

Bodin Ö, Norberg J (2005) Information network topologies for enhanced local adaptive management. Environ Manag 35(2):175-193

Bodin Ö, Crona B, Ernstson H (2006) Social networks in natural resource management: what is there to learn from a structural perspective? Ecol Soc 11(2):253-274

Burt RS (2002) Bridge decay. Soc Netw 24(4):333-363

Burt RS (2005) Brokerage and closure: an introduction to social capital. Oxford University Press, Oxford

Cash DW, Adger NW, Berkes F, Garden P, Lebel L, Olsson P, Pritchard L, Young $\mathrm{O}$ (2006) Scale and cross-scale dynamics: governance and information in a multi- level world. Ecol Soc 11(2):258-274

ClimAlpTour (Alber KAM, Balbi S, Bausch T, Benati A, Bonzanigo L, Cetara, LCC, Clivaz C, Colson A, Cremer I, Dissegna M, Doctor M, Dutto E, Elmi M, Fosson JP, Frigo B, Furlani R, Gallée H, Garbellini L, Gessner S, Giupponi C, Herntrei M, Kolbeck F, Luthe T, Macchiavelli A, Matasci C, Mignone N, Moretto D, Muti S, Pasquettaz C, Pasutto I, Peters M, Peyrache-Gadeau V, Pipan P, Pozzi A, Rutter S, Scheibel C, Schuckert M, Siegrist D, Strobl A, Urbanc M, Venuta, ML, Wyss R) (2011) ClimAlpTour-climate change and its impact on tourism in the Alpine space. Final project report of the Alpine space interreg project ClimAlpTour. Založba ZRC, Ljubljana

Cooper C, Scott N, Baggio R (2009) Network position and perceptions of destination stakeholder importance. Anatol Int $\mathrm{J}$ Tour Hosp Res 20(1):33-45

Costa LDF, Rodrigues FA, Travieso G, Villas Boas PR (2007) Characterization of complex networks: a survey of measurements. Adv Phys 56(1):167-242

Cote M, Nightingale A (2011) Resilience thinking meets social theory: situating change in socio-ecological systems (SES) research. Prog Hum Geogr (online first)

Crona B, Bodin Ö (2006) What you know is who you know? Communication patterns among resource users as a prerequisite for co-management. Ecol Soc 11(2):654-667

Davidson-Hunt LJ (2006) Adaptive learning networks developing resource management knowledge through social learning forums. Hum Ecol 34(4):593-614

Davis GF, Marquis C (2005) Prospects for organization theory in the early twenty-first century: institutional fields and mechanisms. Organ Sci 16(4):332-343

Dawley S, Pike A, Tomaney J (2010) Towards the resilient region? Local Econ 25(8):650-667

Duit A, Galaz V (2008) Governance and complexity-emerging issues for governance theory. Governance 21(3):311-335

Duit A, Galaz V, Eckerberg K, Ebbesson J (2010) Governance, complexity, and resilience. Glob Env Chang 20(3):363-368

Ernstson H, Sörlin S, Elmqvist T (2008) Social movements and ecosystem services-the role of social network structure in protecting and managing urban green areas in Stockholm. Ecol Soc 13(2):365-386

Ernstson H, Barthel S, Andersson E, Borgström ST (2010) Scalecrossing brokers and network governance of urban ecosystem services: the case of Stockholm. Ecol Soc 15(4):568-594

Folke C (2006) Resilience: the emergence of a perspective for socialecological systems analyses. Glob Env Chang 16(3):253-267

Folke C, Hahn T, Olsson P, Norberg J (2005) Adaptive governance of social-ecological systems. Annu Rev Environ Resour 30:441-473 
Fuchs M (2004) Strategy development in tourism destinations: a DEA approach. University of Innsbruck, Innsbruck

Gibson CC, Ostrom E, Ahn TK (2000) The concept of scale and the human dimensions of global change: a survey. Ecol Econ 32(2):217-239

Grabher G (1993) The weakness of strong ties: the lock-in of regional development in the Ruhr area. In: Grabher G (ed) The embedded firm: on the socioeconomics of industrial networks. Routledge, London

Granberg M, Elander I (2007) Local governance and climate change: reflections on the Swedish experience. Local Environ 12(5):537-548

Granovetter MS (1973) The strength of weak ties. Am J Sociol 78(6):1360-1380

Gunderson LH, Holling CS (2002) Panarchy synopsis: understanding transformations in human and natural systems. Island Press, Washington, DC

Hassink R (2010) Regional resilience: a promising concept to explain differences in regional economic adaptability? Camb J Reg Econ Soc 3(1):45-58

Hirschi C (2010) Strengthening regional cohesion: local collaboration networks and sustainable development in Swiss rural areas. Ecol Soc 15(4):363-375

Ingold K, Balsiger J, Hirschi C (2010) Climate change in mountain regions: how local communities adapt to extreme events? Local Environ 15(7):651-661

IPCC (2007) Climate change 2007: impacts, adaptation and vulnerability: working group II contribution to the fourth assessment report of the IPCC, Parry ML, Canziani OF, Palutikof JP, van der Linden PJ, Hanson CE (eds) Cambridge University Press, Cambridge

Janssen MA (2007) An update on the scholarly networks on resilience, vulnerability, and adaptation within the human dimensions of global environmental change. Ecol Soc 12(2):356-381

Kelly PM, Adger WN (2000) Theory and practice in assessing vulnerability to climate change and facilitating adaptation. Clim Chang 47(4):325-352

Kelman I, Lewis J (2005) Ecology and vulnerability: islands and sustainable risk management. Int J Isl Aff 14(2):4-12

Kern K, Bulkeley H (2009) Cities, Europeanization and multi-level governance: governing climate change through transnational municipal networks. JCMS 47(2):309-332

Lebel L, Anderies JM, Campbell V, Folke C, Hatfield-Dodds S, Hughes TP, Wilson J (2006) Governance and the capacity to manage resilience in regional social-ecological systems. Ecol Soc 11(1):562-583

Linnenluecke M, Griffiths A (2010) Beyond adaptation: resilience for business in light of climate change and weather extremes. Bus Soc 49(3):477-511

Linnenluecke M, Griffiths A, Winn M (2012) Extreme weather events and the critical importance of anticipatory adaptation and organizational resilience in responding to impacts. Bus Strateg Environ 21:17-32

Little LR, McDonald AD (2007) Simulations of agents in social networks harvesting a resource. Ecol Model 204(3-4):379-386

Luthe T (2009) Vulnerability to global change and sustainable adaptation of ski tourism-SkiSustain. Report series of the Institute of Outdoor Sports and Environmental Science, vol 25. German Sport University Cologne, Institute for Outdoor Sports and Environmental Science. Umweltbeirat Deutscher Skiverband (DSV), Planegg. Stiftung Sicherheit im Skisport (SIS), Planegg. Available online at http://www.tobiasluthe.de/download/SkiSus tain_download.pdf

Manring SL (2007) Creating and managing interorganizational learning networks to achieve sustainable ecosystem management. Organ Environ 20(3):325-346

Michel J (2001) Erlebnis Berg. Qualitätsanforderungen an Luftseilbahnen und ihre Dienstleistungen. Dissertation at the University of Berne. Institute for Leisure and Tourism (FIF). Berner Studien zu Freizeit und Tourismus Band 39

Martin R, Sunley P (2006) Path dependence and regional economic evolution. J Econ Geogr 6(4):395

MeteoSwiss (2011) Meteorological online data base IDAWEB from the Swiss federal office of climatology and meteorology. https://gate.meteoswiss.ch/idaweb

Newig J, Günther D, Pahl-Wostl C (2010) Synapses in the network: learning in governance networks in the context of environmental management. Ecol Soc 15(4):784-793

OECD (2007) Climate change in the European Alps, vol 1. Organisation for Economic Co-operation and Development OECD, Paris

Oh H, Chung M-H, Labianca G (2004) Group social capital and group effectiveness: the role of informal socializing ties. Acad Manag J 47(6):860-875

Olsson P, Folke C, Hahn T (2004) Social-ecological transformation for ecosystem management: the development of adaptive comanagement of a wetland landscape in southern Sweden. Ecol Soc 13(2):411-423

Olsson P, Folke C, Galaz V, Hahn T, Schultz L (2007) Enhancing the fit through adaptive co-management: creating and maintaining bridging functions for matching scales in the Kristianstads Vattenrike biosphere reserve, Sweden. Ecol Soc 12(1):156-171

Ritter T, Wilkinson IF, Johnston WJ (2002) Measuring network competence: some international evidence. J Bus Ind Mark 17(2/ 3):119-138

Ruiz-Ballesteros E (2011) Social-ecological resilience and community-based tourism: an approach from Agua Blanca, Ecuador. Tour Manag 32(3):655-666

Sandström A, Carlsson L (2008) The performance of policy networks: the relation between network structure and network performance. Policy Stud J 36(4):497-524

Schneider K (2011) Climate change and social network functions. An evaluation of the region Disentis-Sedrun-Andermatt. Masters thesis, University of Applied Sciences HTW Chur

Seilbahnen Österreich (2005) Marketing Forum Seilbahnen Österreich. http://www.seilbahnen.at

Starik M, Rands GP (1995) Weaving an integrated web: multilevel and multisystem perspectives of ecologically sustainable organizations. Acad Manag Rev 20(4):908-935

Stoker G (1998) Governance as theory: five propositions. Int Soc Sci J 50(155):17-28

Vogus TJ, Sutcliffe KM (2007) Organizational resilience: towards a theory and research agenda. In: Donk M (ed) Systems, man and cybernetics. ISIC, IEEE international conference, Montreal, pp 3418-3422

Walker B, Salt D (2006) Resilience thinking: sustaining ecosystems and people in a changing world. Island Press, Washington, DC

Wassermann S, Faust K (1994) Social network analysis: methods and application. Cambridge University Press, Cambridge

Webb C, Bodin Ö (2008) A network perspective on modularity and control of flow in robust systems. In: Norberg J, Cumming GS (eds) Complexity theory for a sustainable future. Columbia University Press, West Sussex, pp 85-111

Weick KE, Roberts KH (1993) Collective mind in organizations: heedful interrelating on flight decks. Adm Sci Q 38(3):357-381

Weick KE, Sutcliffe KM, Obstfeld D (1999) Organizing for high reliability: processes of collective mindfulness. In: Boin A (ed) Crisis management, vol III. Sage, Thousand Oaks

Wenger E (1998) Communities of practice: learning, meaning and identity. Cambridge University Press, Cambridge

Wilbanks T, Leiby P, Perlack R, Ensminger T, Wright S (2007) Toward an integrated analysis of mitigation and adaptation: some preliminary findings. Mitig Adapt Strat Glob Chang 12:713-725

Young KR, Lipton JK (2006) Adaptive governance and climate change in the tropical highlands of western South America. Clim Chang 78(1):63-102 